\title{
Redesigning Nursing Education to Build Healthier Communities: An Innovative Cross-Sector Collaboration.
}

\author{
Beth Ann Swan \\ Emory University \\ Peggy Hilden \\ Kaiser Permanente \\ Nikki West \\ Kaiser Permanente \\ Garrett Chan \\ Healthlmpact \\ Katbry thßs Shaffererdditional works at: https://jdc.jefferson.edu/nursfp \\ Thomas Jefferson University \\ Part of the Nursing Commons \section{Let us know how access to this document benefits you}

\section{Recommended Citation}

Swan, Beth Ann; Hilden, Peggy; West, Nikki; Chan, Garrett; Shaffer, Kathryn; Berg, Judith G;

Dickow, Mary; and Jones, Deloras, "Redesigning Nursing Education to Build Healthier

Communities: An Innovative Cross-Sector Collaboration." (2020). College of Nursing Faculty

Papers \& Presentations. Paper 104.

https://jdc.jefferson.edu/nursfp/104

This Article is brought to you for free and open access by the Jefferson Digital Commons. The Jefferson Digital Commons is a service of Thomas Jefferson University's Center for Teaching and Learning (CTL). The Commons is a showcase for Jefferson books and journals, peer-reviewed scholarly publications, unique historical collections from the University archives, and teaching tools. The Jefferson Digital Commons allows researchers and interested readers anywhere in the world to learn about and keep up to date with Jefferson scholarship. This article has been accepted for inclusion in College of Nursing Faculty Papers \& Presentations by an authorized administrator of the Jefferson Digital Commons. For more information, please contact: JeffersonDigitalCommons@jefferson.edu. 
Authors

Beth Ann Swan, Peggy Hilden, Nikki West, Garrett Chan, Kathryn Shaffer, Judith G Berg, Mary Dickow, and Deloras Jones 
Running head: TRANSFORMING NURSING EDUCATION

Redesigning Nursing Education to Build Healthier Communities:

An Innovative Cross Sector Collaboration

Beth Ann Swan, PhD, CRNP, FAAN ${ }^{1}$

Peggy Hilden ${ }^{2}$

Nikki West, $\mathrm{MPH}^{2}$

Garrett Chan, PhD, RN, APRN, FAEN, FPCN, FCNS, FNAP, FAAN ${ }^{3}$

Kathryn Shaffer, EdD, RN, MSN, CNE ${ }^{1}$

Judith G. Berg, RN, MS, FACHE ${ }^{3}$

Mary Dickow, MPA, FAAN ${ }^{3}$

Deloras Jones, MSN, $\mathrm{RN}^{2}$

${ }^{1}$ Jefferson College of Nursing, Thomas Jefferson University, Philadelphia, PA

${ }^{2}$ Kaiser Permanente, Oakland, CA

${ }^{3}$ HealthImpact, Oakland, CA

Corresponding Author: Beth Ann Swan, bethannswan@gmail.com, 267.315.1424 


\begin{abstract}
Today's healthcare environment requires that registered nurses are prepared for an array of practice settings, providing more care outside of the hospital, and directly in the community. There is increasing focus on wellness and prevention and improving access to care and mental health services for an aging and more diverse population. To improve alignment of education with increasingly complex needs, donor-advised funding supported four prelicensure nursing schools to transform their curriculum. The project guided select schools through a curriculum redesign process emphasizing community and continuum of care. This innovation was consistent with meeting challenges to realize Future of Nursing recommendations.
\end{abstract}




\section{Redesigning Nursing Education to Build Healthier Communities:}

An Innovative Cross Sector Collaboration

Exponential changes in health care delivery are driving the need to transform how registered nurses are educated as many pre-licensure programs continue to focus on acute care settings (RWJF, 2019). Yet most pre-licensure academic institutions and curricula have been slow to respond. In 2015, one state's nursing workforce center partnered with more than 50 statewide thought leaders and held a series of regional convenings to envision the future of nursing, incorporating national, statewide, and regional reports and initiatives. The result was creation of the Nursing Education Plan White Paper and Recommendations for California (HealthImpact, 2016) that articulated five recommendations to redesign the pre-licensure educational system to meet contemporary healthcare needs for Californians. The fifth recommendation was to "provide transformative learning opportunities that prepare nurses for evolving roles in rapidly changing interprofessional practice environments" (HealthImpact, 2016, p.19). The associated strategy identified the need to "design curricula with the capacity to fluidly accommodate the evolving healthcare environment and emerging nursing roles encompassing the continuum of care" (HealthImpact, 2016, p.19).

In 2018, a cross sector team came together to support four schools in an innovative pilot program focused on educating nursing students consistent with the fifth recommendation of the White Paper, with a focus on care in the community. The team included: (a) leaders from a large regional employer who have extensive experience and interest in nursing workforce needs and provided donor-advised funding, (b) two faculty from an academic health sciences university who advised and led faculty and administrators of the four pilot schools through a process, (c) the state's nursing workforce center and action coalition that served as the convener and subject 
matter expert in developing the workforce to be consistent with The Future of Nursing (2010) key messages, and (d) nursing education consultants from the state's licensing and regulatory board who were active participants in helping schools of nursing understand the statutes and regulations in support of curriculum redesign. This paper describes the innovative collaboration that resulted in redesigning curriculum to educate nursing students for community-focused health care delivery.

\section{Request for Proposals and Selection}

To launch the work, $\$ 400,000$ in grant funding was made available to the schools of nursing, faculty consultants, and state nursing workforce center. A total of seven schools were invited to apply for funding. Schools were identified based on their creative and open institutional culture from administration through faculty, broad representation of rural and urban settings, student population of underrepresented groups in nursing, inclusion of community colleges and four-year schools, and demonstrated ability to advance innovation within their organization and community. Based on strength of responses to information requested through a Request for Proposal format, four schools were selected, two offer baccalaureate programs and two offer associate degree programs. Schools are in geographically and compositionally different parts of the state.

\section{Project Team and Components}

Over the course of 15 months, schools were guided and supported by a team of two faculty coaches who successfully transformed pre-licensure curriculum at their academic health sciences university, the state's nursing workforce center and action coalition, three licensing board nursing education consultants, and key leaders from the funding/employer organization.

Five major components were used to help facilitate participant schools' work: (a) monthly 
individual school coaching calls with nursing school directors and faculty representatives, (b) quarterly webinars open to all school faculty and interested stakeholders, (c) two in-person full day intensive educational, community-building sessions, (d) oversight/risk mitigation calls for the support team, and (e) online learning community.

\section{June 2018 Meeting}

A one-day convening, Redefining RN Curriculum to Impact Health of Communities, was held to kick-off the process on June 4, 2018 at the largest health care innovation center in the country. There were 70 people in attendance including direct grantees and other stakeholders interested in nursing education redesign. The goals of the meeting were to energize, inspire, and inform next steps in a curriculum redesign process leveraging the exemplar from the faculty advisors from the academic health sciences university, and provide a unique experience such that participants left with both a new way of thinking and a new community with which to collaborate. The four grantee schools each brought a team of up to 10 people, including directors, faculty, students, existing clinical partners, and community stakeholders. Activities included: (a) leveraging innovative space to foster new thinking around nursing education encompassing knowledge, skills and competencies across settings and the lifespan, (b) sharing examples of recent curriculum development successes, (c) creating a framework for the design process that incorporates both standardization and local needs, and (d) building a learning community.

\section{Monthly Coaching Calls and Quarterly Webinars}

Every month the two faculty coaches met with each school team individually, including the school's licensing board nursing education consultant and the nursing workforce center. For each call, the teams were asked to prepare responses to three prompts, and the prompts were 
different for each call. The first call prompts were: (a) how did you and your faculty get started after the in-person meeting, (b) who are the members of your curriculum redesign team, and (c) how are you engaging external stakeholders, community organizations, and non-profits in your curriculum redesign. Additional prompts included: (a) what is one mutually beneficial goal that is shared between your nursing program and the community organization, (b) what message(s) do you want to communicate, what is unique, different about your redesign, (c) what are your talking points when meeting with your community partners, and (d) identify a success story and describe the "back story" in creating the win-win with the partner.

Topics for the quarterly webinars were: 1) Moving Beyond the Obvious: Community Engagement in Curriculum Redesign, 2) Transitioning to a Concept Based Curriculum: Connecting the Dots, 3) Bring Your Plan of Study Working Session, and 4) Teaching the New Curriculum: Strategies to Get Faculty and Students on Board.

The licensing board nursing education consultants actively participated in the monthly coaching sessions, quarterly webinars, and connected regularly with the schools. The "real time" communication that was established early on has continued with excellent results. This strengthened relationship has fostered problem solving and reduction in barriers. This unique aspect of the project has made a significant difference in the success of the redesign process and the final curriculum approval process from the licensing board.

\section{May 2019 Meeting}

An in-person learning community session took place May 30, 2019 to share accomplishments to date and provide input on next steps. The event, Transforming Nursing Curriculum: Preparing Nurses for Evolving Roles, was held at a community foundation and was a huge success with all four schools, their community partners, and the licensing board 
participating. Keynote speaker Dr. Patricia Benner inspired the group with her presentation, Teaching and Learning... The Living Curriculum to conclude the day. Schools were asked to invite non-traditional clinical partners and their new community partners to contribute to the discussion and shape future direction. Each school presented a comparison of their legacy curriculum and transformed curriculum. Using the power of the learning community, each school received input ideas from their peers and thought leaders.

\section{Online Learning Community}

The state nursing workforce center and action coalition manages the online learning community that was established at the start of the program. This resource repository is dynamic and provides the four schools with access to materials and important documents to facilitate their success on an ongoing basis, as new information, reports, and articles became available, they have been added to the collection.

\section{Program Outcomes and Advancing The Future of Nursing Recommendations}

Faculty and administrators at the four participating schools represented a range of expertise and experience with curriculum redesign. Over $92 \%$ of faculty and administrators agreed that curriculum change was clearly needed, and that the schools would benefit from curriculum redesign. Eighty-five percent agreed that there are real stakeholders needs that make this change necessary, $85 \%$ agreed that the change will help faculty/programs become better equipped to meet students' needs, and $85 \%$ agreed there was a clear vision regarding the change project. All faculty and administrators (100\%) agreed the curriculum redesign project had a high priority for success.

Each school made progress in reaching its goals, in achieving change through a transformed curriculum thus advancing The Future of Nursing recommendations. The schools 
implemented solutions to improve the nursing education system by focusing beyond acute care, across settings of care, including the community, primary care, and public health, and across the lifespan. A curriculum redesign exemplar linked to The Future of Nursing recommendations is described in Table 1. The schools built deeper relationships and higher levels of engagement with an expanded number of clinical partners, both traditional as well as new, creative ideas for non-traditional community placements, such as county health departments, health centers, and non-profits providing care coordination for special populations. Schools are more intentionally focusing on the social determinants of health, health equity, and culture of health concepts in their curriculum. The project is ongoing, and to date, two of the four pilot schools have submitted and received approval from the state licensing board for completing a major curriculum redesign. Three of the four schools have moved to a concept-based curriculum, an approach that differs from the traditional method of learning specific facts in isolation to understanding broader principles that can be applied to a variety of specific examples and settings. An unexpected, positive result is the relationship that was built between the schools and their assigned licensing board nursing education consultants. Together, the schools and nursing education consultants are collaborating to define new, creative, and relevant ways to educate that adhere to regulations. There is an openness to change and trust that has been established among the participants in the monthly coaching calls, with ideas being generated and real/perceived blocks being resolved in real time, and a new appreciation that the curriculum change process is long and non-linear with some quick wins, and no easy fixes.

\section{References}

HealthImpact. (2016). Nursing education plan white paper and recommendations for California. Oakland, CA. Institute of Medicine. (2010). The future of nursing: Leading change, advancing health. Washington, D.C.: The National Academies Press.

Robert Wood Johnson Foundation/AARP Foundation. (2019). Nursing education and the path to population health. Washington, D.C.: Center to Champion Nursing in America. 
Table 1. Curriculum Redesign Exemplar Linked to The Future of Nursing Recommendations

\begin{tabular}{|c|c|c|}
\hline $\begin{array}{c}\text { Legacy } \\
\text { Curriculum } \\
\end{array}$ & $\begin{array}{c}\text { Transformed Curriculum } \\
\text { Highlights } \\
\end{array}$ & $\begin{array}{l}\text { The Future of Nursing } \\
\text { Recommendations }\end{array}$ \\
\hline $\begin{array}{l}\text { - } \text { Quarters } \\
\text { - Traditional } \\
\text { disease-based } \\
\text { model } \\
\text { - Acute care } \\
\text { focus }\end{array}$ & $\begin{array}{l}\text { - Semesters } \\
\text { - Students engaged in redesign } \\
\text { process } \\
\text { - Plan of study begins with community } \\
\text { mental health didactic and } \\
\text { incorporates community mental } \\
\text { health experiences and continuum of } \\
\text { services and added simulation } \\
\text { experiences } \\
\text { - Implemented community } \\
\text { engagement strand with a } \\
\text { community experiential experience } \\
\text { during four of the five semesters } \\
\text { with the same neighborhood } \\
\text { - Students attend local community } \\
\text { meetings } \\
\text { - End of semester debrief among } \\
\text { faculty and community partners } \\
\text { - Change rooted in finding correct } \\
\text { connections, intentionality, and } \\
\text { sustainability }\end{array}$ & $\begin{array}{l}\text { - Need for highly educated } \\
\text { nurses } \\
>\text { Nurses need to attain } \\
\text { requisite competencies to } \\
\text { deliver high-quality care } \\
>\text { Competency in specific } \\
\text { content areas such as } \\
\text { leadership, community, } \\
\text { and public health } \\
>\text { Educated in new ways } \\
\text { that better prepare } \\
\text { students to meet the needs } \\
\text { of the population } \\
\text { - An improved education } \\
\text { system } \\
>\text { New approach and } \\
\text { educational model } \\
\text { developed that responded } \\
\text { to growing information in } \\
\text { the field } \\
>\text { Fundamental concepts } \\
\text { applied across all settings } \\
\text { and across the lifespan } \\
>\text { Competencies in } \\
\text { community settings and } \\
\text { public health addressing } \\
\text { both physical health and } \\
\text { mental health }\end{array}$ \\
\hline
\end{tabular}

